\title{
Los guardabosques reales: inicio de su funcionamiento y la dotación de equipo
}

\author{
EnRIQUe Martínez RuIZ * \\ Magdalena de Pazzis PI Corrales *
}

La Compañía de Guardabosques Reales fue creada en 1761 en Cataluña para ser trasladada a Madrid y repartida en pequeños destacamentos situados en los núcleos de población próximos a los bosques de los Sitios Reales ${ }^{1}$. En enero de 1762 empezarían a prestar servicio inaugurando así un nuevo período en la historia del dispositivo de seguridad de los Sitios Reales. Para cumplir adecuadamente con su misión tendrían que conocer las necesidades y los escenarios donde iban a desarrollar su cometido - lo que les exigiría una relación continua con los habitantes de los núcleos urbanos próximos a esos bosques-, y la prestación del servicio con unos medios y procedimientos que los singularizara, y que a cualquier espectador le permitiera identificarlos como tales agentes. Por eso se les dota con un uniforme específico, cosa lógica en toda unidad militar nueva que se crea con independencia de cualquiera de las ya existentes, y que en ese caso es tanto más comprensible por la peculiaridad del servicio de la Compañía y la naturaleza de los lugares donde iba a actuar, pues en los fundadores hay un decidido propósito de mostrar con los Guardabosques que los Sitios Reales tienen una nueva protección

* Universidad Complutense. Madrid.

Para estas cuestiones remitimos a Martínez Ruiz, E. y PI Corrales, M., «Precedentes a la creación de la Guardia Civil. La Compañía de Fusileros Guardabosques Reales», Cuadernos de la Guardia Civil (1989), n. ${ }^{\circ}$ 2, págs. 119-124; "Creación y organización de la Compañía de Fusileros Guardabosques Reales", en Actas del Coloquio Internacional sobre Carlos III y su siglo. Tomo II. Madrid 1990, págs. 61-74; "Los Guardabosques Reales y su entorno (17621764)», Studia Histórica, vol. 6 (1988), págs. 579-587 y PI CORRALES, M. de P., «Los Guardabosques Reales y el Reglamento de 1784", en Actas del / Seminario Duque de Ahumada: la Guardia Civil: pasado, presente y futuro. Madrid 1989, págs. 55-62. 
encomendada a unos hombres, cuyo uniforme los hacía fácilmente identificables. Ya hemos señalado en otro lugar ${ }^{2}$ algunos de los principios y de las razones que se tuvieron en cuenta para determinar cómo debía ser ese uniforme y también señalabamos cómo entre la documentación que hemos manejado no hemos encontrado los figurines del primer uniforme que recibieron los Guardabosques, de modo que la primera descripción del mismo que encontramos es la que se contiene en el reglamento de 1784, que dice así:

«El (uniforme) de el Fusilero ha de constar de un gambeto de paño azul veinte y quatreno, con buelta y collarin encarnado de grana de Bejar, forro de sarga azul y galon de pita, chupa encarnada con bueltas y collarin azul con el mismo galon y forro de lienzo blanco, chupetin de paño azul, calzon encarnado forrado de lienzo, y boton del peltre, sombrero con galon de plata ancho de un dedo con boton y presilla de los mismo, y escarapela encarnada de estambre, dos camisas de lienzo de gante con bueltas de olan, dos corbatas de seda negras con borlitas a los cabos, dos pares de medias, un par de zapatos, otro de evillas, un par de botines de becerro blanco suave con sus presillas, una bandolera de ante bueno, una mochila de lienzo de media vara en quadro con solapa y tres botones, correa y evilla correspondiente, un portafusil con su evilla, una cartuchera con su petral y charpa, y una bolsita de ante a cada lado".

El mismo reglamento especifica que el vestuario de los Sargentos será igual al de los Fusileros, salvo en las calidades de algunas prendas y materiales, como la del paño (en este caso sería «veinte y seiseno») o la grana (que sería de San Fernando); asimismo se especifica que los galone del gambeto y la chupa serían de media pulgada de ancho y «el sombrero de buena lana con galon de dos dedos de ancho". Y por lo que respecta a los Cabos de Escuadra, la única diferencia sería la de que "el galon del cuello de plata» tendría un dedo de ancho, y como distintivo llevarían dos galones en la vuelta. Por su parte, el tambor y el pífano usarían «los galones de seda de la librea de la Casa Real».

Igualmente el reglamento establecía que «el medio vestuario se compondría de las prendas siguientes»:

«Un sombrero, un par de calzones, una camisa, una corbata, dos pares de medias, un par de botines, un par de zapatos, y un par de evillas, todo de la misma calidad en cada clase que se han prevenido en el vestuario entero".

2 Martínez Ruiz, E. y Pi Corrales, M. de P., «Creación y organización de la Compañía de Fusileros Guardabosques Reales", en Actas del Coloquio Internacional sobre Carlos III y su siglo, Tomo II. Madrid 1990, págs. 61-74. 
Y en lo que respecta al armamento, quedó establecido desde el principio que cada Guardabosque sería dotado con una escopeta, una bayoneta y dos pistolas. Asimismo, en el citado reglamento se especificaba que:

"A mas del vestuario se subministrara con el a esta Compañia una Caja de Guerra con sus baquetas, una bolsa para el Pífano guarnecida de la franja de Casa Real, dos sables para el Tambor y Pífano, y veinte escudos de plata en plancha con las Armas del Rey, para ir renovando los que se inutilicen con la fatiga del servicion ${ }^{3}$.

A pesar de que hasta 1784 no recibe la Compañía una especificación reglamentaria sobre su uniforme y armamento, todo parece indicar que en esa fecha se confirma lo que venía siendo habitual hasta entonces, pues según nos muestra la documentación, las cuestiones relativas a estos dos aspectos menudean en los años anteriores al citado.

No parece que el aprovisionamiento de los Guardabosques se hiciera con puntualidad y desde el principio padecieron unos desajustes entre las prendas y armas que necesitaban y las que les suministraban, como demuestra, sin ir más lejos, un informe que presenta sobre el particular el Capitán Joseph Marty, Jefe de la Compañía, donde refleja:

$\begin{array}{rlr}\text { «Lo que han de tener } & \text { Lo que tienen... } \\ 100 & \text { plazas } & 100 \\ 98 & \text { escopetas } & 98 \\ 196 & \text { pistolas } & 180 \\ 100 & \text { bayonetas } & 91 \\ 100 & \text { charpas } & 98 \\ 100 & \text { bandoleras } & 99 \\ 100 & \text { gambetos } & 100 \\ 100 & \text { chupas } & 97 \\ 100 & \text { calzoncillos } & 97 \\ 100 & \text { faldilletes } & 98 \\ 100 & \text { sombreros } & 99 \\ 100 & \text { corbatines } & 63 \\ 200 & \text { camisas } & 112 \\ 200 & \text { pares de medias } & 104 \\ 100 & \text { pares de zapatos } & \end{array}$

3 Reglamento que ha mandado el Rey expedir para el servicio, disciplina y gobierno de la Compañia de Fusileros Guarda Bosques Reales. Madrid 1784, Artículo 17, págs. 7-9. 
100 pares de botines

100 pares de alpargatas

El mismo oficial explica en su informe el porqué de esos desajustes, ofreciéndonos una serie de pormenores muy ilustrativos de algunas dimensiones de la vida de los Fusileros. En efecto, inmediatamente después de las dos columnas que acabamos de recoger, recalca que a sus hombres les faltan 88 camisas, 37 corbatines, 16 pistolas y 96 pares de medias y añade que lo que más se gasta en el servicio son los calzones. Después, analiza la situación en que se encuentran algunas prendas y armas y explica las razones que las han llevado a ese estado. Así, dice que las escopetas y pistolas están muy maltratadas por su desgaste en el uso de las batidas y «sacadillas» del Rey, algo que estaban acusando muy directamente estas armas, que ya eran viejas cuando se las entregaron a los fusileros. Por otra parte, las pistolas y bayonetas que faltan son las que se han perdido en los montes durante el servicio «por correr y saltar (los Guardabosques) por las peñas y troncos, saliendo del charpon las pistolas y agarrandose por las ramas y zarzas el cubo de las bayonetas". En cuanto a la bandolera y el escudo real que falta, es porque se los robaron a un Fusilero del destacamento de Alcobendas. Todo lo demás -chupas, calzones, corbatines, camisas...-, «se han consumido por las continuas batidas y sacadillas y ojeos del rey con las lluvias, sudor, rasgarse en los troncos y ramas y haberse encendido la polvora a tres diferentes que se quemaron todo un costado de chupa». Ante semejante realidad no resulta nada extraño que, excepto el gambeto, el resto del vestu:ario (especialmente los calzones, corbatines, camisas y medias) esté muy desgastado y lleno de remiendos (cuyo precio en Madrid era muy caro, según anota el Capitán Marty).

La consecuencia que se desprende de todo lo escrito no podía ser otra que la demanda del envío de nuevas prendas, algo a lo que los Guardabosques tenían derecho, pues en el momento en que su Capitán firmaba este escrito, había transcurrido un año y once días desde que la Compañía recibiera el vestuario y armamento: reglamentariamente, los Guardabosques tenían derecho a recibir el medio vestuario, que se les entregaba al año siguiente de recibir el vestuario completo ${ }^{4}$. La entrega de éste y del medio vestuario parece que se desarrolla con normalidad, pues el 23 de junio de 1766 se declara en un documento que cada dos años, el 4 de octubre, se le da entero el vestuario a la Compañía de

4 Informe de la Compañía de Fusileros Guardabosques Reales, San Lorenzo, 15 de noviembre de 1762. Archivo General de Simancas, Sección Guerra Moderna, Legajo 1556. 
Fusileros Guardabosques Reales y cada año intermedio, el 1 de mayo, el medio vestuario; ambas entregas se hacen en función de las relaciones que pasa el Capitán de la Compañía al Inspector General de Infantería ${ }^{5}$. Las noticias sobre el particular en los años siguientes son muy escasas y por su contenido, todo parece indicar que sólo se toca esta cuestión cuando surge alguna anomalía. Es el caso, por ejemplo, de una Orden de 1792 que advierte sobre la entrega del vestuario completo correspondiente a ese año, entrega que tendría lugar el 4 de noviembre en lugar del 4 de octubre según estaba previsto. Sin embargo, este cambio de mes se había establecido por el Reglamento de 1784 que era más específico sobre esta particular cuestion ${ }^{6}$.

Todos los indicios vienen a resaltar que la concesión de las prendas del vestuario con esta frecuencia era absolutamente necesaria, hasta el extremo de que, en ocasiones, el aspecto de los Guardabosques dejaba mucho que desear, pues la dureza del servicio causaba estragos en su atuendo como el propio Capitán de la Compañía comenta al referise a sus hombres, "respecto de ir tan indecentes y derrotados" con ocasión de la recepción del medio vestuario de ese año, que quedó establecido en la siguiente relación:

- «100 pares de calzones de media grana con aforro de lienzo blanco botones de peltre sin cascarilla y charreteras de estambre del mismo color con dos borlitas.

- 100 sombreros de buena lana con galoncitos de plata de un dedo de ancho y su cocanda de estambre encarnada.

- 100 corbatas de seda alistada con sus borlitas al cabo.

- 100 camisas de lienzo de Gante con su sueltas de batista.

- 200 pares de medias de hilo blanco.

- 100 pares de zapato de bezerro suabe.

- 100 pares de alpargatas con cinta azul.

- 100 pares de botines de becerro suave" ?

Además, la vida de la Compañía está jalonada de continuas referencias a esta cuestión, planteada siempre en los mismos términos: el vestuario «se halla muy derrotado y consumido e inútil por el continuo transito de

\footnotetext{
5 El referido documento se encuentra en el legajo ya citado en la nota anterior. En tanto que no se indique otra cosa, los documentos que citemos se entenderá que pertenecen a este legajo.

${ }_{6}^{6}$ El escrito que comentamos está contenido en el Legajo 6183 del Archivo de Simancas, Sección Guerra Moderna.

7 Carta de 10 de septiembre de 1767 firmada por José Marty, enviada con vistas a que el 4 de noviembre se verifique la entrega de las referidas prendas, según estaba determinado.
} 
los bosques, troncos y zarzas espinosas, sirviendo con S.M. en sus reales batidas». Las frases corresponden a una carta de 1768, pero no difieren gran cosa de las que se pueden escribir en otros años. En esta ocasión, el Capitán de la Compañía relaciona el vestuario que se necesita para el total de la dotación al cumplirse un nuevo plazo para la entrega del vestuario completo. Las necesidades quedaban establecidas en los siguientes términos:

Para los 4 Sargentos.

4 gambetos de paño.

4 chupas de grana forradas de lienzo.

4 pares de calzones de grana con charreteras de estambre forradas.

4 sombreros de buena lana con galón de plata ancho de dos dedos, botón y presilla de lo mismo y escarapela de seda».

Para los 12 Cabos.

12 gambetos.

12 chupas de grana.

12 calzones (todas las prendas en las mismas calidades que las anteriores).

Para el tambor y el pífano.

2 gambetos igual que los cabos con galón de seda de librea de la Casa Real.

2 chupas.

2 calzones de lana de Béjar y charreteras de estambre.

Para los 82 fusileros.

82 gambetos (igual que los de los Cabos pero con la diferencia de tener un galón de pita de un dedo de ancho en las vueltas y collarín).

82 chupas (igual a las de los Cabos).

82 calzones.

Además, se incluían en la relación las siguientes prendas:

100 toneletes o faldilletas.

96 sombreros de lana para Cabos, Pífano y Fusileros.

200 corbatines o corbatas negras.

200 camisas de lienzo de Gante con vuelta de batista.

200 pares de medias de hilo blanco.

200 pares de becerro blanco suave.

100 pares de botines de becerro.

100 pares de hebillas de metal.

200 pares de alpargatas de cáñamo.

100 bandoleras de ante con su portacuchillo de monte. 
28 «escudos de plata en plancha con las armas grabadas que faltan porque se los llevaraon los desertores y porque se hicieron pedazos con el continuo rozar del gambeto y por ser muy delgada la plancha".

100 portafusiles con sus hebillas.

100 mochilas de lienzo.

100 «correajes de petral, charpa y cartuchera de 24 de cartuchos con una bolsita a cada lado".

1 caja de guerra con sus baquetas.

1 portacajas y bolsa para el Pífano guarnecida de librea de la Casa Real.

1200 varas para la cinta azul de las alpargatas ${ }^{8}$.

En términos similares se mantienen la tramitación y el desarrollo de este ramo en los años siguientes, encontrándose muy de tarde en tarde alguna variante como la que refleja Juan Miguel Vivas, nombrado Capitán de la Compañía en 1773, quien en el recuento que hace del vestuario necesario en 1776, añade a una relación similar a la anterior lo siguiente:

98 cartucheras con su petral charpa y una bolsita a cada lado.

2 sables para el Tambor y el Pífano.

20 escudos de plata en plancha con las armas reales que se necesitan para reemplazar "los que se inutilizan con el continuo rozar del gambeto" ${ }^{9}$.

Precisamente, en este mismo año Carlos III decidió aumentar en un Sargento, 2 Cabos y 17 Fusileros, la plantilla de la Compañía y eso se tradujo en un aumento de los efectos que deberían entregarse a la misma y que se amplian en las proporciones que ya conocemos ${ }^{10}$.

En definitiva, por lo visto en los documentos que acabamos de reflejar y por el contenido del reglamento de 1784, el vestuario y armamento de cada Guardabosque Real estaría compuesto por los siguientes elementos:

1 charpa

1 gambeto

1 chupa

1 par de calzones

1 sombrero

2 corbatas

s Carta de José Marty, fechada en Aravaca el 1 de junio de 1768

9 Escrito firmado por Juan Miguel Vivas en Aranjuez, el 23 de abril de 1776.

10 El aumento de efectivos se establece por Real Orden de 20 de junio de 1776 , y el vestuario y armamento que corresponden a las nuevas plazas, en la relación fechada en el Puerto de Santa María el 30 de junio de 1776, firmada por el Conde de O'Reilly. 


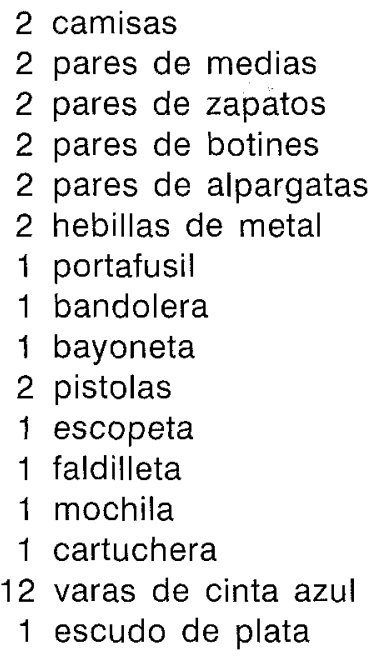

En cuanto a los colores de las distintas prendas del uniforme, hay que señalar su perdurabilidad, pues en 1815 las únicas variaciones que hemos advertido son el cambio del blanco por el negro en el color de los botines, y del rojo por el azul en el de los pantalones ${ }^{11}$. La razón de este cambio la explica el Capitán de la Compañía, por entonces, don Nicolas de Ortuño, quien asegura que el color azul «dura mas en lugar del grana de su primitivo establecimiento", motivo por el que propone dicho cambio, y para que la Tesorería no sufra un quebranto por esta causa, sugiere que se convoque una contrata y que se conceda «al que mas equidad haga en los precios y se cobre proporcionalmente en plazos mensuales" ${ }^{12}$.

Simultáneamente, se ha tenido que atender al reparto de efectivos de la Compañía, pues muy pronto se comprobó que la primera distribución territorial de los Guardabosques resultaba insuficiente para cubrir con eficacia los cometidos que se le habían encomendado. Por eso, ya en 1762 aparecerá un nuevo puesto en EI Pardo que vendría a unirse a los ya existentes. Posiblemente el principal responsable de la creación del nuevo destacamento sería el Duque del Arco, Ballestero Mayor de Su Majestad, quien en abril de ese año, había reclamado algunos fusileros para realizar unas obras en ese lugar. Sea como fuere, lo cierto es que en la distri-

11 No hay ninguna otra novedad en la carta que Nicolás de Ortuño, Comandante de la Compañía entonces, firma el 17 de marzo de 1815, en Aravaca.

12 Carta de Nicolás de Ortuño al Marqués de Belgida, Caballerizo Mayor, fechada en Madrid el 22 de marzo de 1815, en respuesta a la Real Orden de 27 de febrero de ese mismo año, relativa al vestuario de la Compañía. 
bución de efectivos que se publica en 1762 aparece El Pardo con una superioridad manifiesta sobre los demás emplazamientos, salvo Aravaca, porque al nuevo puesto se le dota con 19 Guardabosques, 1 Cabo y 1 Oficial. Los restantes mantenían los 4 Fusileros y 1 Suboficial como responsable, excepto Colmenar que, además, contaba con 1 Oficial. Según esto, en Aravaca quedaban de forma permanente el Tambor, el Pífano, 2 Oficiales, 2 Sargentos, 6 Cabos y 35 Guardabosques ${ }^{13}$.

Desde estos emplazamientos, los Fusileros cumplían con su cometido y acudían a los requerimientos de las autoridades competentes para proteger las jornadas reales. Así, por ejemplo, para vigilar la estancia en El Escorial se ordena que los Fusileros del Colmenarejo, Guadarrama y Galapagar sean destinados al "Resguardo del Real Bosque del Escorial» y quedan a disposición de don Manuel de Cáceres, Guarda Mayor de ese bosque. Igualmente, se ordena más tarde que los efectivos de Galapagar y Guadarrama pasen a fines de abril al Espinar, y que mantengan la vigilancia en las cañadas hasta que acabe la jornada del Rey que se desarrollaría allí. Y se recomienda "que los fusileros hagan las salidas y juntas que tuviese por conveniente (don Manuel de Cáceres) para el resguardo de la caza, leña y prisión de cazadores y leñadores hasta que el rey se vuelva del Escorial a Madrid». En definitiva, su misión consistía en patrullar desde El Escorial hacia los términos de Colmenarejo y Guadarrama para detener a los instrusos que pudiera perturbar la tranquilidad del Rey en su asueto cinegético ${ }^{14}$. El Pardo no mantendría durante mucho tiempo los efectivos tan numerosos que acabamos de señalar, pues en un reajuste de fuerzas no encontramos con que tiene 4 Fusileros - como los demás puestos- y 1 Cabo como máximo responsable. Esto era una realidad plenamente constatada en 1771, año en el que tiene lugar un traslado de la mayor parte de los efectivos de la Compañía, de forma que la guarnición que estaba en El Pardo pasaría a Alcobendas, la de Alcobendas a San Agustín, la de San Agustín a Colmenar Viejo, la de aquí a Guadarrama, la de Guadarrama a Colmenarejo, ésta se trasladaría a Aravaca, y desde Aravaca se enviarían efectivos para cubrir El Pardo ${ }^{15}$.

13 Sobre estas cuestiones ya hemos adelantado algo en nuestro artículo «Los Guardabosques Reales y su entorno (1762-1784)", Studia Histórica. Historia Moderna, vol. VI, 1988, págs. 579 y ss.

Carta al Capitán de la Compañía de Fusileros Guardabosques Reales de 19 de abril de 1762. Recordamos que mientras no se indique lo contrario, esta documentación se encuentra en el Archivo de Simancas, Sección Guerra Moderna, Legajo 1556.

${ }_{15}$ No sabemos en qué día de febrero se hizo esta distribución y reajuste, pues el documento carece de este extremo. 
En la documentación no encontramos ninguna razón de por qué se reducen los efectivos de El Pardo ni de ese traslado simultáneo, prácticamente, de 30 individuos de la Compañía. Tal vez, ello se deba a cuestiones prácticas del servicio, a dificultades en el acuartelamiento y a la conveniencia de que los Fusileros conocieran todos los lugares donde la Compañía prestaba servicio a fin de conseguir de esta forma una mayor eficacia. Lo más probable es que influyeran los tres factores señalados. Resulta evidente que el servicio cotidiano iría perfeccionando sus mecanismos y tal vez se pudieran conseguir los mismos objetivos con menos hombres estables en El Pardo. Que los Fusileros conocieran bien todos los parajes donde podían ser destinados, parece algo tan elemental como obvio; y no podemos descartar problemas en el acuartelamiento, porque el Rey en 1773 ordenaba que los destacamentos de San Agustín, Colmenar Viejo, Guadarrama y El Espinar, se acuertelaran en casas adecuadas, como ya ocurría con los de Alcobendas y Colmenarejo. Y no es sólo una simple preocupación por la comodidad de los Guardabosques lo que hay detrás de la Real Orden, sino un objetivo de mayor alcance como se puede deducir de las palabras del Soberano, "para que estando unidos los fusileros se observe el buen orden y disciplina que corresponde con beneficio y comodidad de los vecinos" ${ }^{16}$. Esto nos hace suponer que hasta esas fechas persistían las dificultades para encontrar un acuartelamiento adecuado y con capacidad suficiente para que todos los Fusileros de un puesto vivieran juntos, en lugar de repartidos por casas particulares.

A veces, las condiciones de vida en un puesto entrañaban cierta dureza, hasta el punto de solicitarse su traslado, solicitud que se denegaba, si lo aconsejaban los imperativos del servicio. Una buena muestra de lo que decimos la constituye la propuesta que se lleva a Carlos III para trasladar el destacamento de Peralejo a Zarzalejo o Valdemorillo, o repartir por mitad sus efectivos en ambas plazas. La petición está basada en la humedad y falta de víveres existente en Peñalejo, pero el Rey no accede porque considera ese lugar idóneo para guardar sus bosques «y contener el paso de los cazadores como se ha verificado por el aumento de la cazas ${ }^{17}$. El puesto de Peralejo había sido establecido por Real Orden de 19 de noviembre de 1780. Las razones de tal decisión acabamos de conocerlas $^{18}$.

16 La Real Orden por toda data lleva la indicación de febrero de 1773.

17 La propuesta y la respuesta regia a la misma tienen lugar en noviembre de 1781.

18 Miguel de Múzquiz comunicó la decisión real en un escrito fechado en San Lorenzo de El Escorial el 19 de noviembre de 1780. Archivo General de Simancas, Sección Guerra Moderna, Legajo 1557. 
Por la fecha en que tiene lugar esta petición, ya se había producido una nueva redistribución de los puestos y un nuevo incremento de los efectivos de la Compañía ${ }^{19}$. En efecto, el 20 de junio de 1776, la Compañía veía que el total de sus componentes se elevaba a 124 individuos ${ }^{20}$, Io que suponía un incremento de 2 Cabos, 1 Sargento y 17 Fusileros. El aumento fue una decisión real encaminada a aumentar la seguridad del Real Sitio de Aranjuez, pues estos efectivos residirían «siempre» en el Real Sitio de Aranjuez a las órdenes del Gobernador del mismo; los nuevos Guardabosques se habían reclutado en los dos Regimientos de Infantería Ligera de Cataluña ${ }^{21}$. No obstante, la idea inicial no debió mantenerse mucho tiempo, si es que llegó a aplicarse, ya que las 124 plazas se reparten de la siguiente forma: el Capitán, 1 Oficial, 2 Sargentos, el tambor o el pífano, 4 Cabos y 33 Fusileros serían los encargados de proteger permanentemente las Jornadas Reales allá donde se produjeran y el resto de los efectivos permanecería en los puestos de:

$\begin{array}{lll}\text { Aranjuez: } & 1 \text { Sargento } & \text { 13 Fusileros } \\ & 1 \text { Cabo } & \\ \text { El Pardo: } & 1 \text { Cabo } & \\ & 9 \text { Fusileros } & \\ \text { Viñuelas: } & 1 \text { Sargento } & \\ & 1 \text { Cabo } & \\ \text { Peralejo: } & 1 \text { Oficial } & \\ & 2 \text { Cabos } & \\ \text { Colmenarejo } & 1 \text { Cabo } & \\ \text { Guadarrama: } & 4 \text { Fusileros } \\ & 1 \text { Cabo } \\ \text { Galapagar: } & 4 \text { Fusileros } & \\ & 1 \text { Cabo } & \\ \text { Alpedrete: } & 6 \text { Fusileros } & \\ & 1 \text { Cabo } & \end{array}$

19 Real Orden de 20 de junio de 1776.

20 Son las mismas plazas que encontramos en la revista que se hace el 24 de mayo de 1792, lo que puede indicar que la Compañía había alcanzado el número que se consideraba idóneo para cumplir el servicio que se le exigía, pues entre 1776 y 1792 median 16 años, plazo más que suficiente para proceder a un reajuste si los efectivos no eran los apropiados, ya sea por defecto o por exceso. Véase el escrito que sobre el particular está contenido en el Legajo 6183 del Archivo General de Simancas, de la sección indicada.

${ }_{21}$ Carta de Miguel de Múzquiz fechada el 18 de julio de 1776. 
Aravaca:

1 Oficial

1 Sargento

el tambor o el pífano
1 Cabo

10 Fusileros

Vemos en la presente distribución cómo Aravaca ha perdido el claro predominio que tenía en lo que a número de efectivos se refiere, potenciándose en cambio, los efectivos de la escolta real. La Compañía estaba, además, dotada con un capellán, un cirujano y un maestro armero ${ }^{22}$.

De la misma forma que ha habido reajustes en los efectivos y acuartelamientos, también existen modificaciones en las retribuciones que los miembros de la Compañía reciben por diversos conceptos. Modificaciones consistentes en incrementos de algunas partidas y aclaraciones respecto a descuentos que experimentan en sus sueldos y a las negativas que, como respuesta a sus demandas, se les da en algunos conceptos. Ya hemos visto los problemas suscitados a la hora de fijar los honorarios de los Guardabosques y sus jefes, su pretendida equiparación con los Fusileros del Resguardo y la solución que se adoptaba en mayo de 1762. Esta solución vino establecida por Real Orden de 2 de abril de ese año en la que se establecía que los Oficiales de dicha Compañía cobrarían la misma paga que los demás de su graduación en el resto del Ejército y las gratificaciones siguientes; de manera que los sueldos serían:

\section{Capitán: 120 reales \\ Teniente: 80 reales \\ Subteniente: 60 reales}

A ios Sargentos se les equiparaba con los de la Casa Real, lo que en orden a sueldos significaba la percepción mensual de 149 reales y 4 maravedises, además del prest y pan enteros. Los sueldos del tambor y el pífano se recortaban algo, pues quedaban en 110 reales y 8 maravedises. El de los Cabos ascendía a los 112 reales y 8 maravedises, mientras que el de los Fusileros se mantenía en los 97 reales y 22 maravedises que ya conocemos, lo que significa un sueldo de tres reales diarios quedándoles mensualmente 7 reales y 22 maravedises para masita, que se le ajustaba cada cuatro meses, como al resto de la Infantería. Por su parte el armero recibía 120 reales al mes, el capellán 200 y el cirujano 30, cargo

\footnotetext{
22 Los datos proceden de un «Estado que manifiesta la fuerza de la expresada Compañía, sus Destinos, su haber de Prest y Pagas su servicio, los Inválidos que se conceden a los individuos que se retiran, en que tiempo se les da el vestuario, su Armamento, la gratificación que se considera para su entretenimiento y demás de que debe cuidar el Capitán de ella». El Estado no lleva fecha, pero por las referencias que su contenido hace a diversas Reales órdenes, debe ser posterior a 1776 ya que incorpora el aumento de efectivos de ese año.
} 
este último que en mayo de 1764 se solicita que se convierta en un miembro permanente de la plantilla de la Compañía ${ }^{23}$.

La tropa no tiene la gratificación de pan por estar comprendida en el haber de prest. Tampoco están libres del pago de las hospitalizaciones que por cada una le cargan:

\begin{tabular}{|c|c|c|}
\hline Al Sargento & 94 & maravedises \\
\hline Al Cabo ... & 62 & " \\
\hline Al Pífano & 62 & $"$ \\
\hline Al Tambor & 62 & , \\
\hline Al Fusilero & 54 & $"$ \\
\hline
\end{tabular}

En los años siguientes de forma más o menos esporádica irán apareciendo disposiciones relativas a diferentes extremos de los ingresos y ventajas que los Guardabosques quieren conseguir. Por ejemplo, en 1766 ya se les reconocía el derecho a unos premios que se les concedían por años de servicio y un poco después, se les facilitaban «cédulas de inválidos en calidad de dispersos" con la retribución económica de 60 reales al Sargento, diez menos a los Cabos y 45 a los Fusileros, concesión que se les hace en consideración a «la fatiga que tienen» y cuyas propuestas, según establecía el Duque de O’Reilly, se presentarían el 1 de junio y el 1 de diciembre de cada año ${ }^{24}$. Por esas mismas fechas se aclara que la Compañía no tiene gratificación de recluta, porque todos sus individuos son voluntarios y sin interés por el reenganche: En cambio, tiene la gratificación de armas, que se abona mensualmente por el armero, para que la Compañía tenga siempre a punto el armamento; por tal concepto, se le pasaban 144 reales y 33 maravedises y medio. Fue precisamente el cargo de maestro armero el que más tardó en consolidarse en esta unidad, ya que bien avanzado 1768 se reconocía que por no tener la Compañía maestro armero, estaba expuesta a retrasar sus servicios, ya que en las batidas reales se rompian muchas armas. Para paliar este mal se contrata entonces a un armero de por 8 pesos sencillos al mes (el mismo sueldo que percibían los maestros armeros de los Regimientos del Ejército) y le incumbía al Capitán abonarle la gratificación que le correspondiera por el trabajo realizado en las piezas y cajas que pusiera a las armas (en lo que tampoco se diferenciaba de sus iguales en los Regimientos) ${ }^{25}$. El 9 de septiembre sentó plaza, finalmente, el interesado.

23 Real Orden de 2 de abril de 1762.

24 Vid. los Decretos de 4 de octubre de 1766 y 26 de diciembre de 1767.

25 Véase el escrito fechado el 3 de septiembre de 1768. 
La carencia de gratificación de recluta mueve a los responsables de la Compañía a buscar algunas subvenciones alternativas que les permitan hacer frente a los gastos que supone el peculiar sistema de recluta de los Fusileros. En efecto, la prescripción reglamentaria de que los Guardabosques tenían que ser naturales de Cataluña motivaba que algunos miembros de la Compañía se trasladaran al Principado, y más concretamente a Barcelona, para cubrir las bajas que se producían. Por esta razón, en 1766 se propone que al no existir dicha gratificación «y faltando este haber no hay otro con que suplir el auxilio de los que van a Barcelona» para encargarse del reclutamiento y de la conducción de los nuevos Guardabosques a sus destinos, fuera «propio de la Real piedad de S.M. que siguiendo la regla de la Infantería tengan los conductores en los días de marcha la mitad de socorro sobre el que les corresponde diariamente y que regulandose por treinta días la marcha a Barcelona y en igual tiempo el regreso, sea del agrado de V.M. mandar hacer este abono al Cabo y Fusilero de que trata esta instancia sin cargo alguno al Capitán». El Cabo en cuestión era Esteban Pujol y el Fusilero Juan Rigau; ambos habían sido designados para reclutar doce hombres en Barcelona, misión que tardaron en cumplir desde octubre de 1765 a febrero de 1766 y, como la Compañía no tenía fondo alguno con que abonarle lo que estaba señalado en las Reales Ordenanzas para estas comisiones, se suplica al Rey se le de la gratificación indicada a fin de que los dos hombres pudieran cubrir los gastos que han tenido en los cuatro meses que duró la recluta ${ }^{26}$. La petición debió atenderse, pues en 1772 , en un documento se dice de pasada que hasta entonces el Rey costeaba de su erario los gastos de recluta y enganche, una solución que satisfacía la demanda de los Guardabosques, aunque no estuviera en consonancia con lo que se practicaba en otros cuerpos y armas ${ }^{27}$.

La prescripción reglamentaria aludida de que los Guardabosques debían ser naturales de Cataluña va a originar dificultades, y no solamente las derivadas de los desplazamientos a efectuar las correspondientes reclutas. En 1772, el Conde de O'Reilly advierte que ante los casos de insubordinación y de irregularidades en el servicio registrados, cuando se produzcan vacantes, los nuevos Guardabosques se «saquen» de los dos Regimientos de Infantería Ligera de Cataluña, «encargando a los Gefes que elixan siempre gente de buena presencia, robustez y demás calidades

26 Escrito fechado el 27 de septiembre de 1766. La petición se hacía mucho después de terminar la misión, probablemente cuando la búsqueda de cualquier otra alternativa había sido infructuosa.

27 Nos referimos al escrito fechado en Madrid el 27 de julio de 1772. 
correspondientes a un destino de tanta confianza». Tal dependencia de los Regimientos Catalanes podía entrañar una alteración perjudicial para éstos, por lo que no debe sorprendernos que, en ocasiones, quisieran mitigar las consecuencias de esta servidumbre. Al menos es lo que se desprende de lo que el Conde de O'Reilly dice al Conde de Riela en el sentido de que «los que entraban eran pocos conocidos y sin el preciso conocimiento de la subordinación y regularidad del servicio", cosa que aspira a remediar para que tenga "la Compañía mucha mejor gente» de la que se conseguiría por otro medio. En cuanto a las complicaciones económicas que pudieran derivarse de este trasvase de hombre, el mismo O'Reilly previene que "como la gratificación es hoy del Rey no resulta perjuicio alguno a los Regimientos Cathalanes, ni hay que hacer el abono» ${ }^{28}$.

Sin embargo, el procedimiento de recluta no era cómodo y el Capitán de la Compañía escribió al Rey el 6 de noviembre de 1775 para exponerle "los inconvenientes que resultan a la Compañía de Guardabosques Reales de su cargo de reemplazar las plazas vacantes con los dos Regimientos" indicados. De esos inconvenientes no era precisamente el menor el que se denuncia de la siguiente forma:

«desde que se reemplazan las plazas vacantes por los dos Regimientos de Cataluña, la mayor parte es viciosa y no de la mejor conducta, pues uno se le ha destinado a presidio por ladrón y otro ha desertado ultimamente, llevándose toda la ropa de un Fusilero que se hallaba en el hospital».

En función de esta exposición, Carlos III resuelve «que desde ahora vuelva la Compañía a admitir Reclutas como antiguamente se hacía, sin que vengan de los citados dos cuerpos, pero quiere S.M. que todos los que se recivan sean honrados, de buena disposición y robustez para la fatiga del campo» ${ }^{29}$.

El interés de mantener el nivel económico de los Fusileros no desaparece nunca en los mandos de la Compañia, de forma que si el paso del tiempo deja desfasado algún concepto, se produce la inmediata petición de actualización. Por ejemplo, es lo que hace Jaime de Salazar en 1795 respecto al prest que disfrutaban sus subordinados. El Capitán ma-

${ }^{28}$ Las dos cartas están fechadas en 1772. La segunda concretamente el 27 de julio. La primera no tiene ninguna indicación de día, pero por su contenido debe ser algo anterior.

${ }_{29}$ Escrito dirigido al Capitán de la Compañía, don Juan Miguel Vivas, fechado el 23 de noviembre de 1775 . 
nifiesta en su escrito la estrechura en la que viven los Guardabosques con el prest y el haber «que actualmente gozan y que no alcanza para el preciso sustento diario»; recuerda que no disfrutan de la ración de pan y tienen que comprarlo al precio de dos reales «quedandoles unicamente 8 quartos para la comida quando hay en la Compañía sugetos que ni sobre prest les basta por su corpulencia»; y añade que, además de estar poco alimentados para el trabajo que realizan, el prest tampoco les alcanza «para el indispensable surtido de las prendas necesarias al aseo personal con que deben presentarse a la vista» del Rey, por lo que algunos de ellos dedican su prest diario al aseo personal para mejorar su aspecto. En apoyo de su petición el Capitán Salazar destaca que, pese a todo, en la Compañía no se ha dado el caso de que algún individuo de los licenciados hay dejado deudas al Tesoro, al contrario de «lo que sucede en los demás cuerpos quando toman sus licencias o retiros quedando debiendo grandes cantidades a sus respectivos Regimientos». Tras tan largo preámbulo Salazar «suplica a V.M. se digne concederles una de las gracias que desean y son el auxilio de pan o el aumento del prest que sea de su Real Agrado".

La carta del Capitán de la Compañía nos informa de que el prest que cobraban entonces sus hombres era el siguiente:

$\begin{array}{lcr}\text { Sargento } & 149 \mathrm{mrs} & 4 \mathrm{mrs} \\ \text { Tambor y Pífano } & 110 ", & 8 " \\ \text { Cabo } & 112 ", & 8 " \\ \text { Fusileros } & 97 " & 22 "\end{array}$

y aclara que al Sargento se le entrega todo el prest en mano y a los demás se les da diariamente tres reales para su sustento, reteniéndose lo restante del prest para masita, como se venía haciendo desde los primeros años del funcionamiento de la Compañía. El mismo escrito recoge que según el asiento vigente, una ración de pan costaba a la Real Hacienda 22 maravedises, lo que suponía que cada individuo desembolsaría al mes por este concepto 19 reales y 23 maravedises y medio. El Rey atiende la demanda de Salazar y declara que "enterado de lo poco que les queda para poder comer y entretenerse especialmente en los tiempos que el pan esta caro, y en consideración del servicio que hacen, y a lo que informa el Capitán, y el Inspector General de Infantería, les concede el haber del pan que les satisfará en dinero al precio de 16 mrs por ración» ${ }^{30}$.

30 La exposición de Salazar está fechada en Aravaca, el 17 de agosto de 1795 y la respuesta del Rey, en San Lorenzo el 21 de octubre. Vid. el Legajo 6185 del Archivo de Simancas, Sección Guerra Moderna. 
Cuando aún no se habían resuelto muchas de las dimensiones internas de la economía y de la administración de la unidad, surge un nuevo elemento de conflicto. Desde el momento de su fundación a la Compañía se le pagaba en concepto de utensilio por cuenta de la Real Hacienda, 20 onzas de carbón diario a cada Sargento y Fusilero y aceite para las lámparas de todas las partidas de Guardabosques destacadas en los Sitios Reales para servir al Rey durante las jornadas al aire libre. A mediados de 1767, el Capitán de la Compañía sabe que el Proveedor de la Corte tiene orden de la Superintendencia General de no abonar ni suministrar ninguna de estas partidas en ninguno de los Sitios Reales y uel destacamento se proveerá de 37 libras de carbón y 24 onzas de aceite diario» en el cuartel de Aravaca, suministro que se considera insuficiente por los mandos de los Guardabosques, pues es

«muy pequeña porcion que repartida a los individuos de ella (la Compañia) toca a cada uno 6 onzas de carbón no cabales al día y mucho menos siendo úmedo, que no tienen para calentar el puchero, quanto menos para cocer sus ranchos. $Y$ considerando la continua fatiga de los de esta Compañía y la prontitud del servicio que hacen, que no les da tiempo a cocer sus ollas con la lentitud de las demas tropas, sino con abundancia de lumbre para comer antes de la hora regular y estar pronto a servir en cualquier instante, y por consiguiente apenas les basta las 20 onzas de carbón que hasta aora se les ha suministrado. Es evidente que no dandoles mas de las 6 onzas no podran en ninguna manera cocer sus ranchos ni comer cosa caliente, que es lo más esencial para mantenerse al soldado sano y robusto para poder aguantar el fatigoso servicio que hacen».

En consecuencia, se suplica al Rey que la Real Hacienda, durante el tiempo en que la Compañía esté destacada en los Sitios Reales sirviendo al Rey, continúe con el suministro de «las 20 onzas de carbón diarias a cada uno; y el azeite correspondiente para las lámparas precisas en aquellos quarteles, como se les a suministrado anteriormente, y se practica con la demás tropa que sirve en dichas jornadas, y se abone a la suplente lo que le falta de las pasadas jornadas" ${ }^{31}$. No tomemos la respuesta a esta demanda, pero al presentarse varios años después de crearse la Compañía y no volverse a plantear con posterioridad a esta fecha, nos hace pensar que las cosas debieron quedar como estaban.

Una nueva ventaja en este terreno consiguen los Guardabosques en 1770 , en que una Real Orden establecía que «deberán gozar de ración

31 Petición fechada en Aravaca, el 23 de julio de 1767. 
de paja y cebada diaria" para el mantenimiento de los caballos de las plazas montadas ${ }^{32}$. En esta misma línea hay que situar la ventaja que se concede al Capitán de la Compañía de Guardabosques para que pueda mantener más holgadamente los dos caballos que necesita «a causa de la continua fatiga del campo y asistencia a todos los Sitios»; tal ventaja consistió en la concesión real de una gratificación mensual de media paga sobre su sueldo y una ración de paja y cebada diaria para su montura ${ }^{33}$. Un poco antes de tal ventaja se había establecido que a los individuos de la Compañía de Guardabosques Reales se les suministrara el mismo utensilio que a los batallones de los dos regimientos de la Guardia que se hallaban de guarnición en Madrid y "en atencion a que los Fusileros tienen que hacer varias comidas respecto al servicio del campo y ser muy corto el utensilio que se les considera, el Rey concede desde el 1 de agosto el mismo utensilio que para la demás tropa del ejército según el reglamento del 27 de octubre de $1760{ }^{34}$.

Años después, las reclamaciones de mejoras económicas para los hombres de la Compañía dejan de referirse a las cuestiones que acabamos de ver (es posible que se hubiera alcanzado en este orden de cosas una situación considerada como aceptable por sus componentes) y se plantean en otro nivel, como la exposición donde se comunica al Rey que los tres reales diarios que se conceden a cada Fusilero no son suficientes «para que se mantengan en el aseo que se requiere ni puedan hacer ranchos con la economia que los regimientos (hacen) por los distintos destacamentos en que se hallan repartidos"; por ello, pedían al Rey que se les concediera el pan de munición de que disfrutan las demás tropas del Ejército. Pero el Soberano no accede a la demanda ${ }^{35}$.

Otra línea en la que se perseguían mejoras era en la relativa a pensiones, viudedades e inválidos. Las concesiones de viudedad van jalonando la vida de la Compañía como consecuencia de las bajas que se producen en acto de servicio, y así sabemos que en el balance que se comunica al Rey a finales de la década de los setenta se concedió una pensión de dos reales diarios a la viuda de un Fusilero que murió en 1768 tras seis años de servicio; que en 1766, murió otro Fusilero tras cinco años en la Compañía, concediendosele a su viuda un real y medio diario, y que la viuda de un Sargento recibió tres reales diarios. En la categoría de los Cabos no se disfrutaba de ninguna viudedad por no haber muerto

\footnotetext{
Real Orden de 18 de junio de 1770.

Tal concesión está fechada en mayo de 1776.

Contenido de la real Orden fechada en julio de 1775.

Real Orden de enero de 1787.
} 
ninguno que estuviese casado ${ }^{36}$. Años después, se concede a la viuda de un Tambor de la Compañía la gracia de dos reales diarios, que perdería si se casaba de nuevo ${ }^{37}$. Por lo que respecta a invalidez, a finales de la década de los ochenta se plantean algunos casos sobre el particular aplicándose un criterio basado en los años de servicio para la concesión o delegación de este tipo de ayudas. Por ejemplo, Salazar, entonces Capitán de la Compañía, en una de sus cartas dice que el Fusilero Francisco Villafranca "es acreedor a la gracia de inválidos y su destino en la clase de dispersos en el Principado de Cataluña»; basa su razonamiento en que el individuo en cuestión estaba enfermo del pecho según las certificaciones expedidas por el médico y el cirujano «y haberse inutilizado en la servidumbre que hace esta Compañía en el campo». En cambio, esta gracia no se le concede a otros Fusileros porque llevaban poco tiempo de servicio ${ }^{38}$. Dos años después, en 1789 , se confecciona una relación de los Fusileros que tiene la Compañía acreedores a la gracia de inválidos, en la que figuran tan sólo dos individuos, ambos Fusileros, uno de treinta y dos años y diez de servicios, que desea retirarse a Bañolas y que padece el achaque de "cansado" el otro, de veintidós años de edad y sólo dos de servicio en la Compañía, está «valdado» y se retiraría a Santa Yecla de Bellalta ${ }^{39}$.

36 Ejemplares que hay en la Compañía del cargo de V.M. de viudedades concedidas a mujeres de individuos de ella. Septiembre de 1778.

37 Concesión hecha en febrero de 1788.

38 Exposición hecha en mayo de 1787.

39 Archivo General de Simancas, Guerra Moderna, Legajo 6182. Escrito fechado el 27 de agosto de 1789 . 